\title{
Fluoride releasing and enamel demineralization around orthodontic brackets by fluoride-releasing composite containing nanoparticles
}

\author{
Mary A. S. Melo • Weslanny A. Morais - Vanara F. Passos • \\ Juliana P. M. Lima • Lidiany K. A. Rodrigues \\ Received: 18 December 2012 / Accepted: 24 July 2013 /Published online: 22 August 2013 \\ (C) Springer-Verlag Berlin Heidelberg 2013
}

\begin{abstract}
Introduction Fluoride-containing materials have been suggested to control enamel demineralization around orthodontic brackets during the treatment with fixed appliances. The improvement of their properties has been made through innovations, such as the application of nanotechnology by incorporation of nanofillers.

Objective This in vitro study evaluated the capacity of fluoride releasing and enamel demineralization inhibition of fluoride-releasing nanofilled cement around orthodontic brackets using an artificial caries biofilm model.

Materials and methods Forty bovine enamel discs were selected by evaluating surface microhardness and randomized into four groups $(n=10)$ : non-fluoride-releasing microfilled composite, fluoride-releasing microfilled composite, resin-modified glass ionomer cement (RMGI), and fluoride-releasing nanofilled composite (FN). After brackets bonding in each disc, the specimens were subjected to a cariogenic challenge through a Streptococcus mutans biofilm model. After the experimental period, the biofilm formed around the brackets was collected for fluoride analysis and the mineral loss around the brackets was determined by integrated demineralization via crosssectional microhardness measurement at 20 and $70 \mu \mathrm{m}$ from the bracket margin. Additionally, samples of each group were subjected to energy-dispersive X-ray spectroscopy (EDX) analysis examined under a scanning electron microscopy (SEM). ANOVA followed by Tukey test were applied for fluoride concentration and mineral loss data, respectively.
\end{abstract}

M. A. S. Melo $\cdot$ W. A. Morais $\cdot$ J. P. M. Lima

L. K. A. Rodrigues $(\bowtie)$

Post-graduate Program in Dentistry, Faculty of Pharmacy, Dentistry and Nursing, Federal University of Ceará, 944 Cap Francisco Pedro Street—Rodolfo TeófiloFortaleza Ceará 60430-170, Brazil

e-mail: lidianykarla@yahoo.com

V. F. Passos

School of Dentistry, University of Fortaleza, Washington Soares

Avenue,1321Fortaleza Ceará 60811-905, Brazil
Results At both distances, only RMGI statistically differed from the other groups presenting the lowest demineralization, although there was a trend to a lower demineralization of enamel around brackets in FN group. Similar condition was found to fluoride concentration and EDX/SEM analysis. Conclusions Under the cariogenic exposure condition of this study, the fluoride-releasing nanofilled material had similar performance to fluoride-releasing microfilled materials.

Clinical relevance The presence of nanofillers in the fluoridereleasing materials studied did not promote further benefits against caries lesion development around brackets and presented inferior demineralization inhibition than the resinmodified glass ionomer material.

Keywords Nanotechnology · Biofilm · Fluoride-releasing materials · Orthodontic brackets $\cdot$ EDX element analysis

\section{Introduction}

One of the main problems related to orthodontic treatment is the development of demineralized areas around brackets during fixed orthodontic therapy [1], which is reported to occur in short time and with high rates among patients [2]. The fixed orthodontic appliance components as brackets, arch wires, Oring, and metal ligature ties do create additional retentive sites, encouraging biofilm accumulation [3]. Microbiological changes after brackets placement towards increased levels of cariogenic species such as Streptococcus mutans [4], which may result clinically in a higher enamel demineralization adjacent to orthodontic appliances. Over time, this condition associated with patient's caries risk factors may result in active white spot lesions, and if untreated, cavitated caries lesions can occur [5].

Adjunctive preventive strategies to avoid the increase of caries risk for patients with fixed orthodontic treatment involve the use of fluoride, a well-documented anticaries agent, 
able to promote remineralization of early caries and to inhibit demineralization $[6,7]$. One of these preventive methods is focused on development of various fluoride-releasing materials to be used as orthodontic bonding agents [8]. This is particularly interesting since these materials with sustained release of fluoride ions will be applied adjacent to the brackets, an area with great association to enamel demineralization. This way, materials for the adhesive fixation of the brackets also were formulated to release fluoride, typically by the inclusion of fluoride-containing compounds such as fluoroaluminosilicate glasses, yttrium fluoride, stannous fluoride, or organic amine fluorides [9].

Nowadays, there are numerous available fluoridecontaining orthodontic cements in the dental market including glass ionomers, resin-modified glass ionomer cements, polyacid-modified composites (compomer), and composites $[10,11]$. The glass ionomer materials are highlighted by their anticariogenic properties due to their capacity to release and store fluoride [12]. However, the disadvantage of glass ionomer material for orthodontic use is its low bond strength to dental substrate leading to more bracket debond failure [12]. The inclusion of filler in composite for bonding orthodontic brackets has been done in order to increase the shear bond strength to the enamel structure without reducing the low flowability, well-known characteristic of these materials [13].

The application of nanotechnology has changed the size scale in dental research materials. Dental materials approaching nanoscale dimensions exhibit unusual properties with numerous applications [14]. The nano-sized material particles can be dispersed in higher filler concentrations and polymerized into the resin system to increase filler loading of composites. It has led to the optimization of individual material characteristics and claims impart distinct advantages, such as superior polishability and better mechanical and wear properties [15]. Additionally, the distribution of nanoparticles results in a smoother, satisfactory consistency, and adequate flowability of the material [16]. Due to the benefits from the nanofiller incorporation, the manufacturers of the recently commercially available nanofilled resin-based orthodontic bonding agent claims that it is a material with ideal flowability able to show significantly improved surface smoothness and high immediate shear bond strength values of metal brackets bonded to bovine enamel. Those entire features combined with fluoride release capacity.

The ability to release fluoride is quite a complex process, and different factors such as the fluoridated particle type and size, different matrices, setting mechanisms, as well as silane treatment may influence the process of ion migration $[17,18]$. It is possible that the adoption of nanofiller loading might have implications on fluoride-releasing mechanism of bonding orthodontic brackets due to specific features promoted by presence of nanofiller. Numerous studies on the amount of fluoride provided by fluoride-releasing materials and its effect on enamel demineralization have been published [19, 20], but an insight into fluoridated composite resins containing nanofillers is still lacking. The purpose of this study was to investigate the concentrations of fluoride found in a S. mutans cariogenic biofilm grown around orthodontic brackets bonded with fluoridated composite containing nanofillers and to compare it to a fluoride-releasing microfilled composite, a non-fluoridereleasing microfilled composite and a resin-modified glass ionomer cement. Another aim was to evaluate the extent of enamel demineralization around the brackets after these materials had been used.

\section{Materials and methods}

Four commercially available materials, including a nonfluoride-releasing microfilled composite (MC) that was chosen to be the negative control group for fluoride release, a fluoride-releasing microfilled composite (FM), a resinmodified glass ionomer cement (RMGI) as a positive control group, and a fluoride-releasing nanofilled composite (FN) were used in the experiment (Table 1).

\section{Specimen preparation}

Forty polished enamel discs (diameter $5.0 \mathrm{~mm}$ and thick $2.0 \mathrm{~mm}$ ) were prepared from the labial surface of 90 freshly extracted, sound bovine mandibular incisors (Fig. 1). The bovine teeth were stored in $0.01 \%(w / v)$ thymol solution at $4{ }^{\circ} \mathrm{C}$, and they were used within 1 month after extraction. The discs were prepared using a water-cooled diamond core drill (trephine) and a bench-type drilling machine (Schulz S/A, Joinville, SC, Brazil). The samples were serially flattened with water-cooled abrasive discs $\left(320,600\right.$, and 1,200 grit $\mathrm{Al}_{2} \mathrm{O}_{3}$ papers; Buehler, Lake Bluff, IL, USA) and polished with felt paper and diamond spray $(1 \mu \mathrm{m}$; Buehler $)$ mounted in a polishing machine (Arotec SA, Cotia, SP, Brazil). After sample preparation, the discs were kept in refrigerated and humidity environment prior the experiments.

The surface Knoop hardness number (KHN) was determined by performing five indentations (FM 100, Future Tech, Tokyo, Japan) in the center of the enamel surface, with parameters set at $50 \mathrm{~g}$ and $5 \mathrm{~s}$ for selection and randomization distribution purposes. Enamel discs presenting mean microhardness values $(302.4 \pm 22.1 \mathrm{KHN})$ were randomly assigned in each group $(n=10)$ according to a computer generated randomization list.

A bracket clamp (Ref. 75.01.022; Morelli ${ }^{\circledR}$, Sorocaba, SP, Brazil) was used to hold and keep the standard edgewise incisor metal brackets (Morelli ${ }^{\circledR}$; slot 0.018 in.) in position on the most central area of the enamel disc surface after using the cements according to the respective manufacturer's instructions for each 
Table 1 Commercial materials used in this study

\begin{tabular}{|c|c|c|c|c|}
\hline Group/material & Type & Composition & Batch no. & Manufacturer \\
\hline $\mathrm{MC} /$ natural ortho & $\begin{array}{l}\text { Non-fluoride-releasing } \\
\text { microfilled composite }\end{array}$ & $\begin{array}{l}\text { BisGMA, glass borosilicate, UDMA, silic, } \\
\text { barium glass, PEGMA, DMAEMA, camphorquinone, } \\
\text { hidroxitoluene, and pigments }\end{array}$ & 10111434 & $\begin{array}{l}\text { Novo DFL, Rio de } \\
\text { Janeiro, RJ, Brazil }\end{array}$ \\
\hline $\begin{array}{l}\text { FM/orthodontic } \\
\text { fill magic }\end{array}$ & $\begin{array}{l}\text { Fluoride-releasing } \\
\text { microfilled composite }\end{array}$ & BisGMA, methacrylic acid esters, fluorosilicate glass & $016 / 10$ & $\begin{array}{l}\text { Vigodent AS, Rio de } \\
\text { Jainero, RJ, Brazil }\end{array}$ \\
\hline RMGI/vitremer & $\begin{array}{l}\text { Resin-modified glass } \\
\text { ionomer cement }\end{array}$ & $\begin{array}{l}\text { Polyacrylic-itaconic acid with pendant methacrylate, } \\
\text { water, HEMA, fluoroaluminosilicate glass }\end{array}$ & 0707500147 & $\begin{array}{l}\text { 3M ESPE, Denatal } \\
\text { products, Saint } \\
\text { Paul, MS, USA }\end{array}$ \\
\hline FN/orthocem & $\begin{array}{l}\text { Fluoride-releasing } \\
\text { nanofilled composite }\end{array}$ & $\begin{array}{l}\text { Methacrylate monomers such as BisGMA, TEGDMA, } \\
\text { phosphate methacrylates, stabilizers, fluorosilicate glass, } \\
\text { camphorquinone, co-initiator and silicium dioxide } \\
\text { nanoparticles }\end{array}$ & 040410 & $\begin{array}{l}\text { Dentscare Ltda., } \\
\text { Joinville, SC, } \\
\text { Brazil }\end{array}$ \\
\hline
\end{tabular}

HEMA hydroxyethyl methacrylate, BisGMA bisphenol glycidyl methacrylate, UDMA urethane dimethacrylate, TEGDMA tetraethylene glycol dimethacrylate; PEGMA poly(ethylene glycol) dimethacrylate, DMAEMA dimethylaminoethyl methacrylate

material (Table 1). Except for RMGI group, which was not etched, a conventional etching procedure with $37 \%$ phosphoric acid was performed and the bonding materials were applied to the bracket base and pushed against the enamel surface. In order to standardize bonding pressure and cement thickness, a 453.6-g Gillmore needle was held vertically on the bracket while excessive material around the bracket base was removed with a clinical probe and the material was then light-activated for $20 \mathrm{~s}$ from the mesial and the distal sides with a LED (Optilight LD Max (Gnatus, Ribeirão Preto, SP, Brazil) with a power density of $600 \mathrm{~mW} / \mathrm{cm} \mathrm{[2]} \mathrm{at} \mathrm{a} \mathrm{fixed}$ distance and angle to the surface.

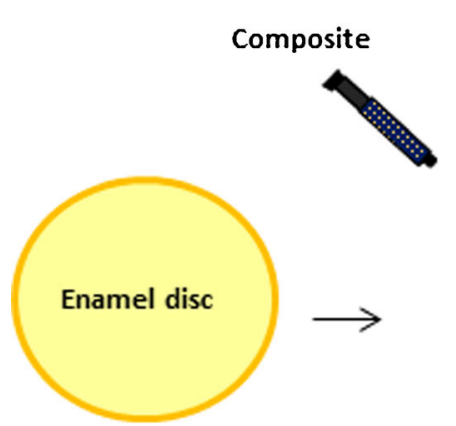

a
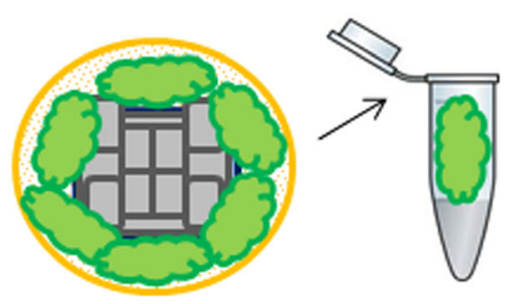

Fluoride concentration in biofilm

e

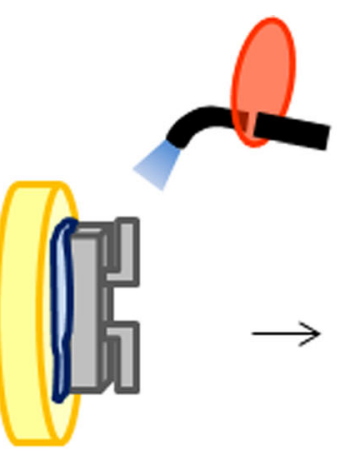

b

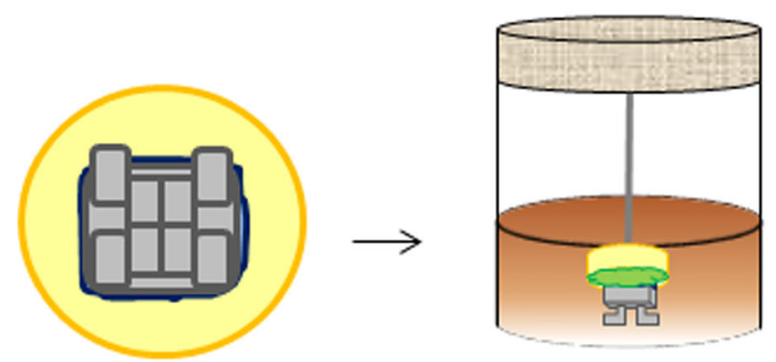

C d

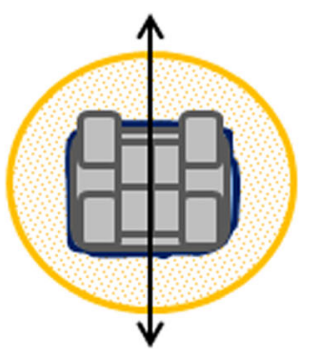

SEM/EDX analysis

Fig. 1 Schematic diagram illustrating the set up for this study. $A$ enamel disc samples ( $5 \mathrm{~mm}$ diameter); $B$ bonding procedures. $C$ Brackets bonded on central area. $D$ Fixation of the slabs in the device (5-day microbial

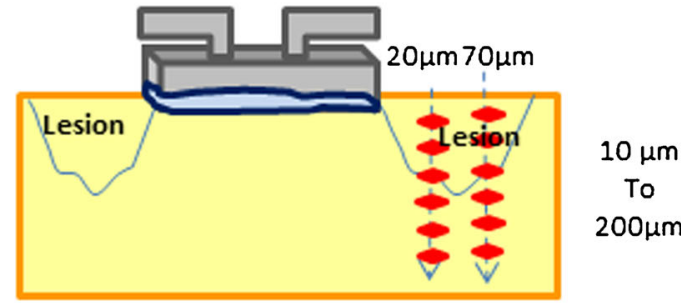

Cross-sectional microhardness analysis

g

model). $E$ Biofilm removal for fluoride analysis. $F$ Demineralized enamel area around brackets submitted to SEM/EDX analysis. $G$ Transversal cut to cross-sectional microhardness analysis 


\section{S. mutans microbial biofilm model}

The enamel bracket set, which provide minimal bonding materials beneath the brackets and similarly mimics the clinical situation, was prepared for this study [10]. The sets were fixed in the lids of glass container vessels with plastic rods, immersed in sterile distilled water, and sterilized prior to inoculation for biofilm growth as described by Zanin et al. [21]. S. mutans strain UA159 was first grown in an overnight culture of Brain Heart Infusion medium (BHI, Difco, Sparks, $\mathrm{MD}, \mathrm{USA}$ ) in a $5 \% \mathrm{CO}_{2}$ atmosphere (Thermo Fisher Scientific Inc., Waltham, MA, USA) to prepare the inoculum to grow mono-specie biofilms. Each enamel disc was placed into an individual container, which was filled with $5 \mathrm{~mL}$ of BHI, supplemented with $5 \%$ fresh prepared sucrose $(w / v)$ [22]. Inoculation of each BHI-containing recipient was performed only once on the first day. Every $24 \mathrm{~h}$, the medium was replaced with pre-warmed fresh BHI with $5 \%$ sucrose during 5 days. The inspection for contamination of the cultures in the media was verified everyday using Gram staining and plating samples onto a new fresh BHI agar media.

\section{Concentrations of acid-soluble fluoride in the biofilm}

After experimental period, the biofilms grown around the brackets were removed for fluoride analysis. The fluoride content in the plaque samples was measured according to the method described by Cury et al. [23]. Briefly, their wet weight was verified after completely removing the biofilms with a sterile scalpel, placing them in preweighed microcentrifuge tubes. The plaque samples and microcentrifuge tubes were weighed and final weights registered. The weights were obtained by subtracting the weight of the microcentrifuge tubes from the final value. Following this step, $0.5 \mathrm{M}$ hydrochloric acid solution $-\mathrm{HCl}$ $(0.50 \mathrm{~mL} / 10 \mathrm{mg}$ of wet biofilm) was appended. After extraction for $3 \mathrm{~h}$ at room temperature via agitation, the samples were centrifuged and TISAB II solution (containing $20 \mathrm{~g}$ $\mathrm{NaOH} / \mathrm{L}$ ) was added to supernatant in order to maintain $\mathrm{pH}$ 5.0 and to eliminate the interference effect of complexion ions [24]. The amount of acid-soluble fluoride $(F)$ was determined electrochemically using a fluoride-sensitive electrode (model 96-09; Orion Research, Cambridge, MA, USA) and an ion analyzer Orion EA-940. The standard solutions were used to plot the calibration graph. All determinations were performed in triplicate and the fluoride concentration expressed as micrograms per milligram of biofilm.

\section{Cross-section microhardness analysis}

Enamel discs were longitudinally sectioned through the center of the bracket. One of the remaining halves of each slab was randomly selected to be analyzed. It was embedded in acrylic resin, the cut surface being exposed, for subsequent flattening and polishing, respectively. Microhardness was measured using a Knoop indenter with $25 \mathrm{~g}$ load for $5 \mathrm{~s}$. Each three lanes of 15 indentations was made in duplicate (each side of bracket), which the lanes were 20 and $70 \mu \mathrm{m}$ distant from the bracket margin [25]. The $50 \mu \mathrm{m}$ distance between the lanes was established to minimize interactions between neighboring marks. The first ten indentations were spaced $10 \mu \mathrm{m}$ from the previous one and the last ones at $20 \mu \mathrm{m}$ intervals. Integrated demineralization $(\Delta \mathrm{S})$ was calculated according to Sousa et al. [25].

\section{SEM/EDX analysis}

In order to investigate alterations in chemical composition (element quantities) contained in the enamel sample, scanning electron microscopy (SEM)/energy-dispersive X-ray spectrometer (EDX) analysis was performed for all groups. After biofilm removal, the demineralized samples were rinsed and stored in a desiccator with silica gel for at least $2 \mathrm{~h}$ to remove remnants of water. After that, samples were mounted on SEM stubs with a conductive double-sided adhesive carbon tape previously on the analysis and inserted into a vacuum chamber. Five points in each surface were selected around the bracket. The system used in this study presents one EDX detector used for qualitative and quantitative microanalysis. The EDX detector is the third generation, the X-flash- $6^{\circledR}$ that does not require liquid nitrogen cooling and is about 10 times faster than the conventional $\mathrm{Si}(\mathrm{Li})$ detectors. The X-rays have to pass the radiation entrance window of the detector before entering the active volume of detector. Only this detector was used in EDX analysis. Normalized high resolution spectra of the main elements' concentration in weight percent were performed and later calculated by an EDX using the backscattered electron collector attached to a scanning electron microscope (TESCAN Model VEGA IIXXMU, Brno, Czech Republic) operating at $30 \mathrm{kV}$ and working distance of $20 \mathrm{~mm}$. Data acquisition and analysis were performed using Quantax 800 software (Bruker AXS, Karlsruhe, BadenWürttemberg, Germany).

Statistical analysis

Statistical analyses were performed with SPSS for 13.0 Windows (SPSS Inc. Chicago, IL, USA). The normality and homogeneity were checked for each response variable. For fluoride concentration and elemental concentration, one-way ANOVA and Tukey's post hoc tests were applied. For $\Delta \mathrm{S}$ and cross-section microhardness analysis (CSMH) per depth, data were transformed using Box-Cox power transformation to the linear equation as suggested by the software [23]. ANOVA and Tukey tests were performed at a significance level of $p<0.05$. 


\section{Results}

Concentrations of acid-soluble fluoride in biofilm

Group RMGI exhibited significantly higher fluoride amounts in biofilm compared to the other tested materials $(p<0.05)$, as expected. The FN group released more fluoride compared to the FM, but afterward, both materials exhibited similar fluoride concentrations, which were not significantly different $(p>0.05)$ (Table 2). Group MC expressed the lowest value.

\section{$\mathrm{CSMH}$}

$\Delta \mathrm{S}$ related to RMGI group was statistically lower $(p<0.05)$ in relation to all groups. The findings show that there was a trend to lower demineralization of enamel around brackets fixed by the FN group comparing to $\mathrm{FM}$ and $\mathrm{MC}$ groups, but the difference among them was not statistically significant (Table 2). The microhardness data at each depth from the enamel surface are expressed in Fig. 2.

\section{SEM/EDX analysis}

In the EDX analysis, the main elements observed in the enamel were calcium $(\mathrm{Ca})$, phosphorus $(\mathrm{P})$, oxygen $(\mathrm{O})$, and fluorine $(\mathrm{F})$. Minor quantities of other elements: sodium $(\mathrm{Na})$, magnesium $(\mathrm{Mg})$, chlorate $(\mathrm{Cl})$, silica $(\mathrm{Si})$, and carbon $(\mathrm{C})$ were also observed in the present study. Elemental mappings showed calcium and phosphorus primarily detected, while fluorine and oxygen were identified in reduced amounts. Means and standard deviation of percentage of elemental concentration in weight (weight percent) detected in the samples are summarized in Fig. 3. A quantitative element analysis revealed no statistically significant differences in $\mathrm{Ca}, \mathrm{P}$, and $\mathrm{O}$

Table 2 Mean and standard deviations of fluoride concentration (microgram per gram wet biofilm) and demineralization at studied distances for each tested material

\begin{tabular}{lccl}
\hline Group & \multirow{2}{*}{$\begin{array}{l}\mathrm{F}(\mu \mathrm{g} / \mathrm{g} \text { wet } \\
\text { biofilm })\end{array}$} & \multicolumn{2}{c}{$\Delta \mathrm{S}$ at distance from bracket base } \\
\cline { 3 - 4 } & & $20 \mu \mathrm{m}$ & $70 \mu \mathrm{m}$ \\
\hline MC $(n=10)$ & $0.27(0.08)^{\mathrm{b}}$ & $5,320.44(1,241.06)^{\mathrm{a}}$ & $4,661.94(1,615.80)^{\mathrm{a}}$ \\
FM $(n=9)$ & $0.91(0.56)^{\mathrm{b}}$ & $5,204.19(1,761.33)^{\mathrm{a}}$ & $4,573.67(122.77)^{\mathrm{a}}$ \\
RMGI $(n=8)$ & $10.50(4.20)^{\mathrm{a}}$ & $876.55(440.80)^{\mathrm{b}}$ & $1,392.37(916.74)^{\mathrm{b}}$ \\
FN $(n=10)$ & $1.48(1.24)^{\mathrm{b}}$ & $4,017.63(1,872.54)^{\mathrm{a}}$ & $4,228.56(1,990.69)^{\mathrm{a}}$ \\
\hline
\end{tabular}

The same superscript letter indicate no statistically significant difference between the indicated groups $(p>0.05)$

$M C$ non-fluoride-releasing microfilled composite, $F M$ fluoride-releasing microfilled composite, $R M G I$ resin-modified glass ionomer cement, $F N$ fluoride-releasing nanofilled composite content among the groups $(p>0.05)$; exception to $\mathrm{F}$, which presented a significantly higher amount in RMGI group.

\section{Discussion}

The incorporation of nanoparticles in resin material may allow the production of materials for the adhesive fixation of brackets with better flowability and higher mechanical properties than for microfilled materials. Also, this process could alter characteristics of the ion-releasing materials $[17,26]$. The in vitro study mainly showed that the fluoride-releasing composite containing nanoparticles for bonding orthodontics brackets exert similar performance of the microfilled composite in relation to fluoride-release and anticaries effect. This showed that nanofiller incorporation did not improve the fluoride release and consequently did not alter the anticaries potential of this material.

In the present study, the microfilled control material used in this study (natural ortho) was chosen since it presents similar composition to microfilled control material refereed in previous orthodontic studies (Transbond XT). Besides, although microradiography is considered as gold standard method for determining mineral loss, microhardness analysis was used due to its great correlation demonstrated by excellent linear relation between square root of $\mathrm{KHN}$ and the mineral volume percent [27]. Additionally, microhardness presents sensitivity to detect the demineralization on enamel subsurface areas as the artificially caries lesions produced in the present study. It is important to remember that even though polishing procedures change natural enamel surface, roughness is important for the exact hardness measurement being a requirement for performing surface microhardness analysis, which was carried out for standardization and selection of the samples. Thus, polishing procedures were submitted to all samples, consequently applying this variable to all groups not interfering in the present results.

According to KHN data, enamel demineralization in vitro was inhibited to a certain degree in our study. Among the tested materials, the control group RMGI exhibited significantly higher performance in all performed analysis compared to the other tested materials. In agreement with other studies $[28,29]$, our results have demonstrated that resin-modified glass ionomer materials showed a fluoride-releasing capacity sufficient to promote lower enamel mineral loss over the tested composite resin materials [30]. This was an expected outcome since the total amount of fluoride released differs significantly between the resin-modified glass ionomer cements and the composite resins. It has been suggested that this superior performance of RMGI is attributed to some factors as the acid-base setting reaction between the fluoride-containing aluminosilicate glass powder base and the polyacid liquid results in the liberation of fluoride ions 
Fig. 2 Mean \pm standard deviation of the mean values $(n=10)$ of enamel Knoop hardness according to the materials and depth of analysis at $20 \mu \mathrm{m}$ (a) and at $70 \mu \mathrm{m}$ (b) from the edge of the bracket base. Small letters indicate statistically significant difference between groups at each distance $(p<0.05)$
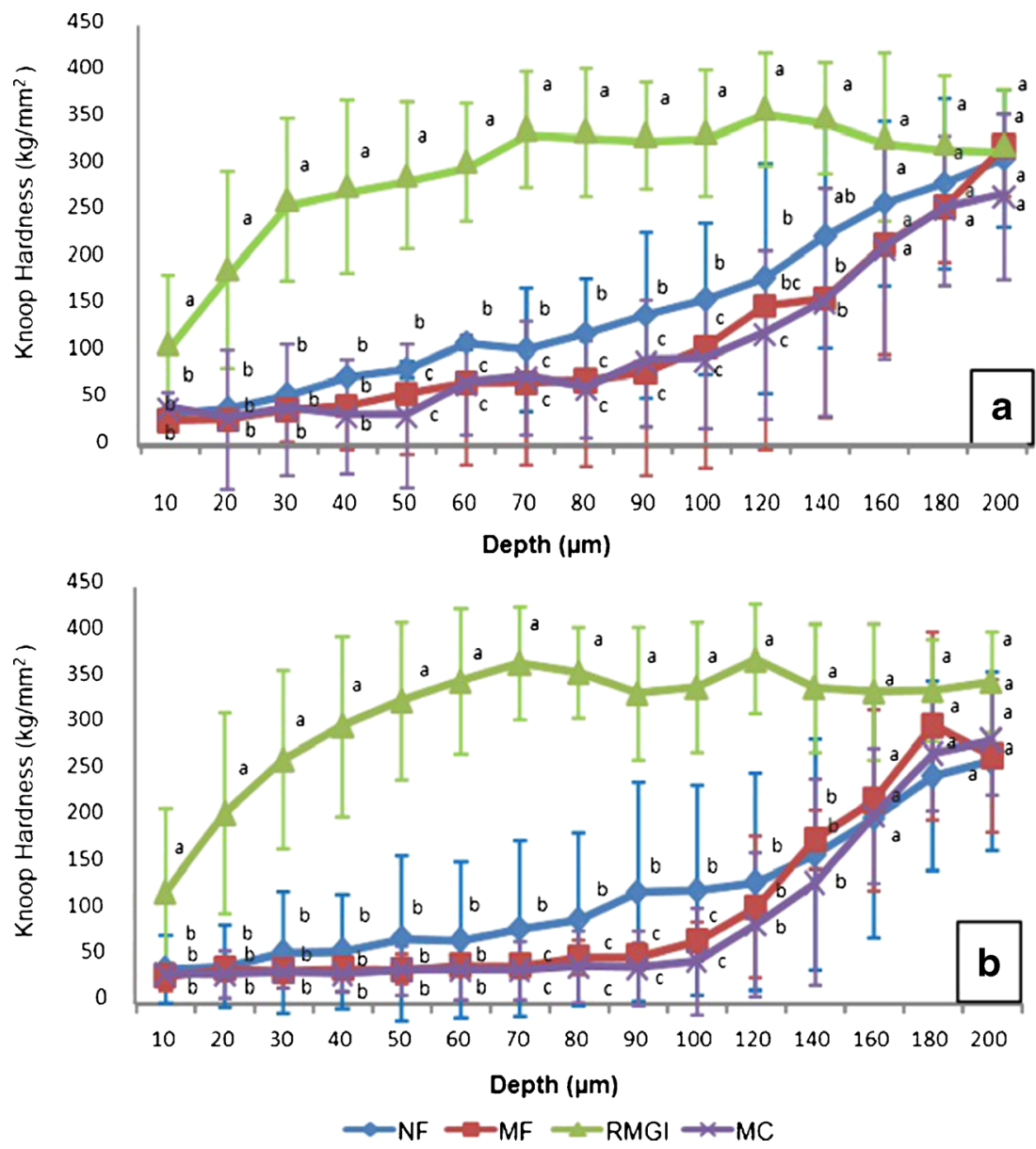

[29]. In poly-salt matrix, fluoride ions can be bound in strong complexes with the metal ions, especially aluminum and the pore liquid, in which the fluoride ions are loosely bound and free to move [31].

In our results, KHN for $50-120 \mu \mathrm{m}$ in depth at both analyzed distances showed significant difference for FN group expressing a trend to better performance of fluoridereleasing nanofilled composite than microfilled materials. The $\Delta \mathrm{S}$ and fluoride concentration data from $\mathrm{FN}$ group also supported this condition; however, they were not significantly different. Only few previous studies investigated fluoride release from nanomaterials. In a previous study, Kusgöz

Fig. 3 Means and standard deviation of percentage of elemental concentration in weight (weight percent) of the main elements found in enamel around the brackets $(n=10)$. Asterisk indicates statistical significant difference

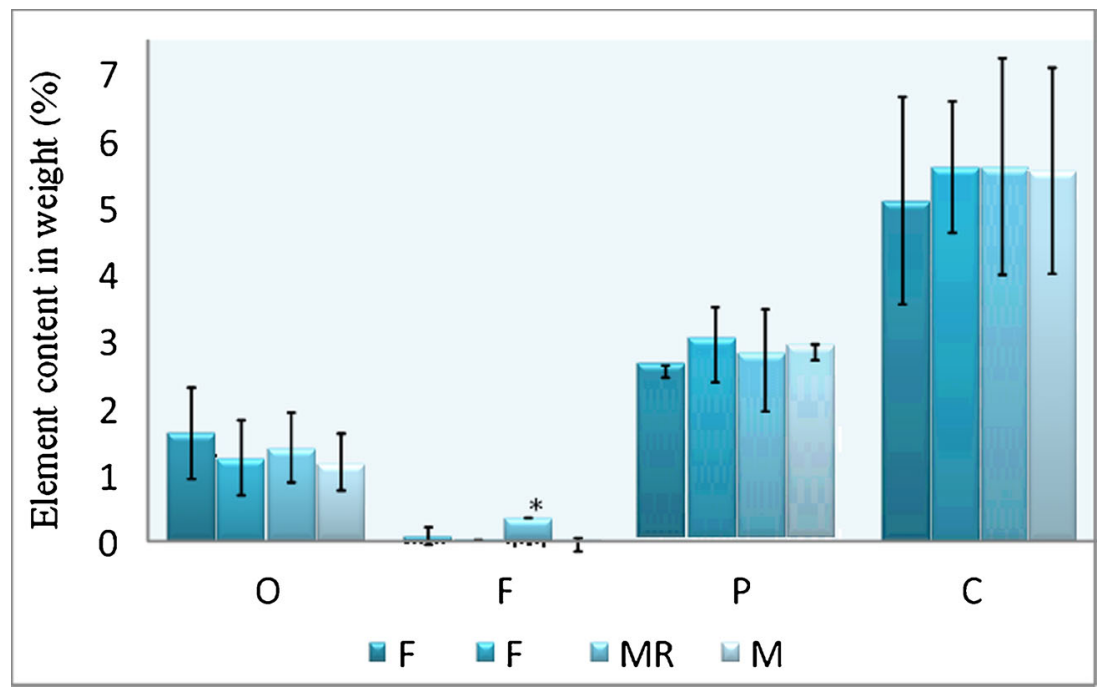


et al. [32]. compared fluoride release of a nanofilled resinbased fissure sealant and an unfilled resin-based fissure sealant. The authors observed that the nanofilled sealant released a bit more fluoride than the unfilled sealant, but these results were not significantly different. These finding are consistent with results of the present study, showing that there is no significant influence on ion fluoride release, but it was able to show higher values than microfilled materials. It can be hypothesized that nanoparticles present in resin matrix of commercial materials can be related to this situation since the studied fluoride-releasing nanofilled composite presents $100 \%$ of its reinforcement particles (silicon dioxide) in nanoscale.

On the other hand, Xu et al. [33]. showed that a nanocomposite containing calcium fluoride $\left(\mathrm{CaF}_{2}\right)$ had a higher fluoride release capacity when compared to the control. This fact may be related to the nano- $\mathrm{CaF}_{2}$ surface area, which presented a surface area nearly 20 -fold higher surface area than a traditional $1 \mu \mathrm{m} \mathrm{CaF}$. This clearly suggests that the size of particles from fluoride source itself presents more relevance for an anticaries effect than the simple presence of nanoparticles in resin matrix.

Fluoride release from composite resin materials is based on the diffusion process where initial leaching of fluoride from glass particles in the surface layer of the material may account for this mechanism. Fluoride ions diffuse through fluid and plaque from the composite to the adjacent enamel surface [34]. The SEM/EDX analysis explored the possibility of different ion diffusion rates from fluoride-containing nanomaterials to the enamel adjacent to bonded bracket and consequently alteration in chemical composition of enamel around the tested materials. The amounts (weight percent) of fluoride found for both fluoride-releasing composite resins, regardless of the presence of nanoparticles, were very low or undetectable. Although other methods might be used to determine firmly bound $\mathrm{F}$ formed in enamel such as removing an enamel layer by acid action, the SEM/EDX analysis currently used may be considered reproducible since similar results were found with fluoride-releasing composite resins by Gjorgievska et al. [18] in a study that aimed to determine the extent to which ions released from fluoride-containing dental restorative materials migrated through the enamel. Besides, the use of acid to determine firmly bound $\mathrm{F}$ in enamel could introduce bias in microhardness analysis due to demineralization justifying the use of the nondestructible SEM/EDX analysis. In relation to the calcium and phosphorus content in the surface enamel around the brackets, the values were similar in all groups showing that no material was able to promote a more significant diffusion of ions in the enamel surface.

Overall, the present evidences that RMGI present anticaries effect are based on $\Delta \mathrm{S}$ data obtained by microhardness analysis. This way, our results showed that under the conditions of this investigation, only RMGI was capable of decreasing demineralization around orthodontic brackets and the inclusion of nanofillers fluoridated composite resin did not provide greater inhibition of demineralization.

Future research should focus in applying the nanotechnology to preventive dentistry in attempt to improve fluoridereleasing capacity of dental materials. Until then, oral hygiene and other regular fluoride sources should be suggested for the orthodontic patient.

Acknowledgments The authors gratefully thank José Júnior da Alves da Silva for his assistance with SEM/EDX analysis and Institute of Research, Development and Innovation (IPDI) for providing the SEM equipment. The first and second authors have received scholarships during this study from $\mathrm{CNPq}$ (\#141791/2010-1) and CNPq/PIBIC/ UFC, respectively.

\section{Conflict Of Interest Statement None declared.}

\section{References}

1. Mitchell L (1992) Decalcification during orthodontic treatment with fixed appliances - an overview. Br J Orthod 19:199-205

2. O'Reilly MM, Featherstone JDB (1987) Demineralization and remineralization around orthodontic appliances: an in vivo study. Am J Orthod Dentofacial Orthop 92:33-40

3. Demling A, Elter C, Heidenblut T, Bach FW, Hahn A, SchwestkaPolly R, Stiesch M, Heuer W (2010) Reduction of biofilm on orthodontic brackets with the use of a polytetrafluoroethylene coating. Eur J Orthod 32(4):414-418

4. Corbett JA, Brown LR, Keene HJ, Horton IM (1981) Comparison of Streptococcus mutans concentrations in non-banded and banded orthodontic patients. J Dent Res 60(12):1936-1942

5. Al Mulla AH, Al Kharsa S, Kjellberg H, Birkhed D (2009) Caries risk profiles in orthodontic patients at follow-up using cariogram. Angle Orthod 79(2):323-330

6. Derks A, Kuijpers-Jagtman AM, Frencken JE, Van't Hof MA, Katsaros C (2007) Caries preventive measures used in orthodontic practices: an evidence-based decision. Am J Orthod Dentofacial Orthop 132(2):165-170

7. Benson PE, Parkin N, Millett DT, Dyer FE, Vine S, Shah A (2004) Fluorides for the prevention of white spots on teeth during fixed brace treatment. Cochrane Database Syst Rev. (3):CD003809.

8. Cacciafesta V, Sfondrini MF, Tagliani P, Klersy C (2007) In vitro fluoride release rates from 9 orthodontic bonding adhesives. Am J Orthod Dentofacial Orthop 132(5):656-662

9. Mystkowska J, Marczuk-Kolada G, Leszczyńska K, Ryszard Dąbrowski J, Karaś J (2009) Fluoride release and antibacterial activity of self-made composite materials for dental fillings. Solid State Phenomena 147-149:801-806

10. Chin MYH, Sandham A, Rumachik EN, Ruben JL, Huysmans MCDNJM (2009) Fluoride release and cariostatic potential of orthodontic adhesives with and without daily fluoride rinsing. Am J Orthod Dentofacial Orthop 136:547-553

11. Rogers S, Chadwick B, Treasure E (2010) Fluoride-containing orthodontic adhesives and decalcification in patients with fixed appliances: a systematic review. Am J Orthod Dentofacial Orthop 4:390.e1-8, discussion 390-1

12. Gandolfi MG, Chersoni S, Acquaviva GL, Piana G, Prati C, Mongiorgi R (2006) Fluoride release and absorption at different $\mathrm{pH}$ from glass-ionomer cements. Dent Mater 22:441-449 
13. Passalini P et al (2010) Mechanical properties of one and two-step fluoridated orthodontic resins submitted to different $\mathrm{pH}$ cycling regimes. Braz Oral Res 24(2):197-203

14. Chen MH (2010) Update on dental nanocomposites. J Dent Res 89(6):549-560

15. Sumita BM, Wu D, Brian NH (2003) An application of nanotechnology in advanced dental material. J Am Dent Assoc 134:13821390

16. Kumar PS, Savadi SKRC (2011) Jins John nanodentistry: a paradigm shift-from fiction to reality. J Indian Prosthodont Soc 11(1):1-6

17. Wiegand A, Buchalla W, Attin T (2007) Review on fluoridereleasing restorative materials-fluoride release and uptake characteristics, antibacterial activity and influence on caries formation. Dent Mater 23(3):343-362

18. Gjorgievska E, Nicholson JW, Grcev AT (2012) Ion migration from fluoride-releasing dental restorative materials into dental hard tissues. J Mater Sci Mater Med 23(7):1811-1821

19. Xu HHK, Moreau JL, Sun L, Chow LC (2008) Strength and fluoride release characteristics of a calcium fluoride based dental nanocomposite. Biomaterials 29:4261-4267

20. Asmussen E, Peutzfeldt A (2002) Long-term fluoride release from a glass ionomer cement, a compomer, and from experimental composite resins. Acta Odontol Scand 60:93-97

21. Zanin IC, Lobo MM, Rodrigues LK, Pimenta LA, Höfling JF, Gonçalves RB (2006) Photosensitization of in vitro biofilms by toluidine blue $\mathrm{O}$ combined with a light-emitting diode. Eur J Oral Sci 1:64-69

22. Melo MAS, Paula DM, Lima JPM, Borges FMC, Steiner-Oliveira C, Nobre-dos-Santos M, Zanin ICJ, Barros EB, Rodrigues LKA (2010) In vivo photodynamic antimicrobial chemotherapy in dentine contaminated by cariogenic bacteria. Laser Phys 20(6):1504-1513

23. Cury JA, do Amaral RC, Tenuta LMA, Del Bel Cury AA, Tabchoury CPM (2010) Low fluoride toothpaste and deciduous enamel demineralization under biofilm accumulation and sucrose exposure. Eur J Oral Sci 118:370-375
24. Tenuta LM, Zamataro CB, Del Bel Cury AA, Tabchoury CP, Cury JA (2009) Mechanism of fluoride dentifrice effect on enamel demineralization. Caries Res 43(4):278-285

25. Sousa RP, Zanin IC, Lima JP, Vasconcelos SM, Melo MA, Beltrão HC, Rodrigues LK (2009) In situ effects of restorative materials on dental biofilm and enamel demineralisation. J Dent 37(1):44-51

26. Mitra SB, Dong WU, Holmes BN (2003) An application of nanotechnology in advanced dental materials. J Am Dent Assoc 134:1382-1390

27. Kielbassa AM, Wrbas KT, Schulte-Mönting J, Hellwig E (1999) Correlation of transversal microradiography and microhardness on in situ-induced demineralization in irradiated and nonirradiated human dental enamel. Arch Oral Biol 44(3):243-251

28. Ahn SJ, Lee SJ, Lee DY, Lim BS (2011) Effects of different fluoride recharging protocols on fluoride ion release from various orthodontic adhesives. J Dent 39(3):196-201

29. Tay WM, Braden M (1988) Fluoride ion diffusion from polyalkenoate (glass-ionomer) cements. Biomaterials 9:454-456

30. Baliga MS, Bhat SS (2010) Effect of fluorides from various restorative materials on remineralization of adjacent tooth: an in vivo study. J Indian Soc Pedod Prev Dent 28(2):84-90

31. Verbeeck RM, De Maeyer EA, Marks LA, De Moor RJ, De Witte AM, Trimpeneers LM (1998) Fluoride release process of (resinmodified) glass-ionomer cements versus (polyacid-modified) composite resins. Biomaterials 19(6):509-519

32. Kuşgöz A, Tüzüner T, Ulker M, Kemer B, Saray O (2010) Conversion degree, microhardness, microleakage and fluoride release of different fissure sealants. J Mech Behav Biomed Mater 3(8):594-599

33. Xu HH, Moreau JL, Sun L, Chow LC (2010) Novel $\mathrm{CaF}_{(2)}$ nanocomposite with high strength and fluoride ion release. J Dent Res 89(7):739-745

34. Hicks J, Garcia-Godoy F, Donly K, Flaitz C (2003) Fluoridereleasing restorative materials and secondary caries. J Calif Dent Assoc 31(3):229-245 